\title{
Preimplantation Factor PIF-1
}

National Cancer Institute

\section{Source}

National Cancer Institute. Preimplantation Factor PIF-1. NCI Thesaurus. Code C95890.

A synthetic version, known as PIF-1, of the peptide Preimplantation Factor (PIF), an embryo-secreted peptide, with potential activity against Graft-versus-Host Disease (GVHD). PIF-1 is believed to have wide-ranging activity on the immunologic system, including a whole host of immunologic changes that resemble pregnancy, in which there is neither graft-versus-host or host-versus-graft disease between the mother and the embryo. Replication of the immunologic profile of pregnancy through the administration of PIF-1 may thus benefit patients undergoing bone marrow transplant (BMT) who experience graft-versus-host disease (GVHD). Native embryonic PIF has been found to have a multi-targeted effect on various aspects of the immune system, coordinated so that there is a successful embryonic implantation and a successful pregnancy. 